\title{
"SEM ANTAGONISMO DE IDEIAS A UNIVERSIDADE ESTÁ FADADA MESMO A SER UMA BOLHA!"
}

\author{
Entrevista com Aurelian Craiutu ${ }^{1}$
}

\section{Revista Malala (RM)}

Ainda sabendo que se trata de uma discussão complexa e que toda definição pode ser genérica, podemos começar com a definição de intelectual. Como você definiria um intelectual?

\section{Aurelian Craiutu (AC)}

Neste ponto a etimologia da palavra pode ser importante. Intelectual vem de intellectualis, relativo ao entendimento. Um intelectual é alguém que quer entender, através da razão, o que está por trás, o que se esconde para além do que podemos enxergar e entender do mundo. Nós todos temos opiniões e ideias, mas são poucos que têm conhecimento. Portanto, os intelectuais são aqueles que têm opiniões e testam as opiniões, as crenças, as conjecturas com o vértice da razão, produzindo uma análise imbuída de lógica, que transcende, que vai além do senso comum. De certa forma, um intelectual é alguém que lembra a figura filosófica de Sócrates, que gostava de se pensar pela analogia da mosca, alguém que voa e transita como se fosse a figura do outsider e do estrangeiro, alguém capaz de observar sem vícios e que desafia as crenças, que as coloca à prova. Por alto, essa seria uma definição de intelectual. Agora, muitos acadêmicos se entendem como intelectuais, mas, na verdade, eles não são; são "profissionais". Não é preciso ser acadêmico para ser intelectual. Agora, se pensarmos na figura do "intelectual público", isso pode complicar um pouco nossa definição. 0 intelectual público é aquele que participa de debates públicos e de uma tradição ligada à França de intelectuais públicos como Jean Paul Sartre, Raymond Aaron, Merleau Ponty e outros tantos dos anos de 1950 e 1960. E a noção francesa de intelectual é bem conhecida e bem disseminada. Infelizmente, essa era dos intelectuais públicos já não existe mais. Portanto, o papel dos intelectuais hoje é bem diferente do que era há 50 anos, mas a definição que fica é a de alguém que busca, que almeja, que desafia a essência da realidade.

\section{RM}

Interessante você mencionar a figura dos intelectuais públicos, pois neste mesmo número da Revista Malala temos uma entrevista com Russel Jacoby, que apresenta um

1 Professor de ciência política da Universidade de Indiana em Bloomington, EUA. Resumo do currículo disponível em: https://polisci.indiana.edu/about/faculty/craiutu-aurelian.html.

Entrevista realizada por Ariel Finguerut, membro do Conselho Editorial da Revista Malala. A entrevista ocorreu por Skype no dia 28/9/2018. Transcrição e tradução de Ariel Finguerut. 
argumento claro e enfático sobre a morte dessa figura dos intelectuais públicos . Você concorda com a tese do Jacoby?

\section{AC}

De fato, a era dos intelectuais públicos se foi. E essa tese aparece em outros autores. Bernard-Henri Lévy, ele próprio uma espécie de intelectual público, já declarou o fim desse campo e chega ao mesmo ponto. E nisso há um novo tipo de intelectual. Jacoby também aponta para isso. Com a expansão da internet, estamos em uma era da disseminação das publicações eletrônicas e, com isso, há um excesso: muita gente publicando, mas pouca gente lendo. Se esse ativismo eletrônico é uma forma de intelectual, não sei; o debate é aberto. Mas aquela era dos intelectuais que associamos a figuras como Sartre ou Aaron se foi.

\section{RM}

E como diferenciar o intelectual que é, digamos, um professor universitário daquele que almeja o processo decisório, que assessora políticos, governos, etc.? E, no mais, como pensar essa figura que escreve e usa de todos os instrumentos disponíveis no mundo virtual? Isso não seria parte do trabalho intelectual?

\section{AC}

Sim, isso faz parte, mas devemos fazer a distinção entre intelectuais e comentaristas. Especialmente na mídia eletrônica, temos um campo fértil para os comentaristas, pessoas dispostas a expressar suas opiniões políticas sobre qualquer coisa. Minha definição de intelectual talvez seja mais próxima do que Raymond Aaron considerava como seu ofício. Ele não se considerava partidário e, ao fazer sua análise política, se colocava numa posição capaz de criticar todos, de todos os lados do espectro ideológico. Hoje, muitos que escrevem na mídia são partidários, defendem posições caras a determinados grupos ou espectros ideológicos, não são imparciais nem apartidários, especialmente em se tratando do debate que envolve poder e aqueles que o almejam. Diante disso tudo, eu fico com a ideia de que ser um intelectual está mais para uma vocação, algo que se busca e que exige equilíbrio e cuidado. Novamente me lembro de Aaron, que era extremante cuidadoso nas análises e assim o foi como um analista da política francesa por quase 40 anos.

\section{RM}

Um tema que certamente também foi caro a Aaron é o da violência e de como os intelectuais lidam com esse tema, às vezes a justificando, a relativizando ou tardando a condená-la. Como você entende essa relação entre intelectuais e a violência?

\section{AC}

Bom, é preciso estabelecer alguns parâmetros para poder pensar e discutir esse tema. Uma distinção é pensarmos em termos de categorias de pensamento "políticas" 
e "ideológicas". Os que operam na categoria política tendem a condenar toda forma de violência e, como posso colocar (...), são contrários a mudanças radicais na vida social. E, nesses termos, a violência raramente é algo aceitável, exceto talvez em algumas determinadas circunstâncias. Já aqueles que pensam pela categoria ideológica podem encontrar justificativas para a violência que levariam aos objetivos que almejam. É como aquela metáfora: "Para fazer uma omelete é preciso quebrar alguns ovos". E, se começa com um ovo, depois dois, três, quatro (...) e a omelete nunca está perfeita, exigindo mais e mais ovos. E, em busca dessa "omelete perfeita", se justifica quebrar mais e mais ovos. É isso que acontece em termos de justificar a violência em nome de uma ideologia. E historicamente os intelectuais estiveram propensos a fazer isso! E isso tem que ser dito.

\section{$\mathbf{R M}$}

Esse campo ideológico que faz parte e que afeta o trabalho dos intelectuais me leva a uma outra pergunta, sobre a mudança de lado em termos ideológicos. Por que intelectuais mudam de lado? Como, por exemplo, do marxismo para o conservadorismo.

\section{AC}

Essa é uma boa pergunta e é uma discussão difícil. Se não me engano, foi [Ralph Waldo] Emerson que disse: "A consistência é o hobgoblin ${ }^{2}$ das mentes pequenas". Ter consistência na política é provavelmente um luxo restrito a alguns poucos criminosos que são tão consistentes na busca de seus objetivos - pense em Hitler ou Stalin - que se dispõem a sacrificar tudo em nome disso. Eu admiro aqueles que, diante de novos fatos, novas pesquisas, novas informações, estão dispostos a mudar de opinião e a repensar suas posições. E nesse ponto lembro-me novamente de Aaron, que cita uma importante lição que aprendeu com o filósofo José Ortega y Gasset. Quando perguntado se era de direita ou esquerda, ele respondeu com uma frase que se tornou memorável: "Ser de direita ou de esquerda a vida toda é uma forma de morte súbita, como um infarto". É preciso entender e saber interpretar a realidade e ajustar nossas atitudes a essa realidade. Nesses termos, não tenho problema em relação a "mudar de lado" ou "mudar de posição". Mas é preciso cuidado. De fato, há o oportunismo. Muda-se de lado ou de opinião em busca de certos benefícios, não porque os novos fatos exigem uma nova postura, mas por oportunismo. Aaron começou como um estudante de esquerda e ao longo da vida caminhou para o centro. No final, ele estava falando a "língua da esquerda" para o público de direita e a "língua da direita" para o público da esquerda. É uma posição desconfortável e não creio que seja uma coincidência o fato de que seu último curso no Collège de France, em 1978, chama-se "Liberdade e Igualdade", ou seja, ele estava argumentando pela importância de ambos os conceitos. Liberdade é um conceito caro à direita e, igualdade, um conceito caro à esquerda. 0 que ele argumentava é que não seria possível focar um conceito esquecendo

2 Nota do tradutor: Na mitologia celta e no folclore irlandês, hobgoblin é um tipo de duende. Para alguns, um duende mais traiçoeiro que os demais e, para outros, também mais agressivo que os demais. 
o outro. Outro pensador que considero importante nessa discussão é Jean-François Revel (o historiador da Revolução Francesa). Ele começou como comunista, mas a intervenção soviética na Hungria lhe mostrou a verdadeira face do comunismo e ele mudou depois disso. Mario Vargas Llosa é um outro exemplo. É mais difícil alguém começar na esquerda e depois mudar para a direita, mas certamente há casos do caminho contrário. No geral, eu diria que é bom mudar de posição, é uma forma (às vezes dura) de aprender com a realidade. Não há nada fixo ou imutável naquilo que é de fato real.

\section{RM}

Mas a universidade traduz essa realidade? Não é relativamente fácil ser um radical nas universidades? Muitas vezes, as universidades criam círculos viciosos, seja para financiamento, seja para legitimidade, não é?

AC

Sim, com certeza. As universidades, especialmente nos EUA, são grandes bolhas. Funcionam como câmaras de eco. E isso é uma pena. Quem está dentro e faz parte da instituição está protegido e, de certa forma, pode usufruir de certa proteção - e com isso podemos, muitas vezes, falar o que nem sempre as pessoas querem ouvir. Mas essa liberdade que temos nas universidades precisa ser dosada com responsabilidade. É preciso saber dosar diferentes pontos de vista. Muitos olham para os professores de esquerda e veem radicalismo (que, na direita, também ocorre). Isso é reflexo de uma mentalidade, de delimitação de campos. E nesse ponto considero importante que os acadêmicos aprendam o que John Stuart Mill escreveu em On Liberty: há ali um belo segundo capítulo no qual ele fala que não devemos silenciar ninguém porque a posição que silenciarmos pode conter uma grande verdade e, se a silenciarmos, perderemos a oportunidade de aprender com ela. E nos EUA há um debate sobre liberdade de expressão e sobre o que se tornaram as universidades (...), bolhas, ecos, etc. Sem antagonismo de ideias a universidade está fadada mesmo a ser uma bolha! E não estou falando só da importância do debate, mas é preciso que haja uma genuína intenção de entender e debater com ideias opostas, diferentes das nossas. Eu, como professor, posso falar de minha experiência pessoal lecionando nas universidades há mais de 20 anos e percebo que as pessoas não gostam de ouvir ou de levar em consideração argumentos e ideias que chocam ou se diferem dos que trazem de partida. As pessoas se sentem mais à vontade quando estão em grupos de afinidade. Por exemplo: quem é mais de esquerda quer estar entre pessoas de esquerda e assim por diante. E esses grupos tendem a desqualificar os demais: a esquerda vê conspirações na direita, a direita vê "comunismo" em todo lugar, etc. e isso é algo muito pernicioso; portanto, considero ser muito importante cultivar essa abertura ao diálogo, à conversa, tentando envolver as pessoas numa troca de ideias diferentes entre posições distintas. E isso pode acontecer em todos os níveis, desde os seminários dos cursos de graduação até o processo decisório da universidade. É interessante porque, na academia, fala-se muito 


\section{entrevista}

em "pluralismo", "diversidade", mas, na prática, não vemos muito disso. A academia não faz o que prega.

\section{$\mathbf{R M}$}

Acabamos escrevendo para quem já concorda com nossos argumentos, não é verdade?

\section{AC}

Sim, é verdade. Infelizmente, isso só se agravou com as publicações eletrônicas. É bom ter novas plataformas e poder chegar a novos públicos. Contudo, acaba sendo uma pregação a convertidos. E isso cria um círculo vicioso: seguimos aqueles com quem concordamos e somos seguidos por quem concorda conosco. É a lógica dos likes (risos). E, conforme as associações que ocorrem nas redes sociais, isso afeta nossas próprias redes de relações. Às vezes alguém se associa com uma pessoa da qual não gostamos e pensamos: "Não quero estar ligado a essa pessoa" ou "O que eu vou aprender com essa pessoa?". Retomando Mill, essa seria uma postura errada. Até hoje, na minha modesta experiência, eu tento cultivar círculos de relação diversos. Claro, não sou perfeito, mas levo a sério a ideia de tentar conversar e dialogar com pessoas de diferentes grupos com posições distintas. Claro que isso tem um risco em jogo - às vezes, ao conversar comigo, eles estão correndo o risco de conversar com pessoas do outro lado (com posições diferentes).

No meu livro ${ }^{3}$ discuto o caso do cientista político italiano Norberto Bobbio. Ele foi um intelectual por quem tenho grande admiração. Era de esquerda, não era comunista, mas passou toda sua carreira acadêmica em diálogo com os comunistas. Bobbio pensava com clareza, um apaixonado por lógica e ele praticava o que escrevia, ou seja, ele entendia que o papel dos intelectuais era fomentar dúvida mais do que certezas. Ele se recusava a pensar em termos ideológicos e a cair na tentação - que hoje é muito comum - daqueles intelectuais que se julgam a medida de todas as coisas. É muito comum hoje encontrarmos pretensos intelectuais com a postura ao estilo "eu sei", "eu avisei", "eu estava certo", etc., Bobbio, assim como Aaron, é um bom exemplo de intelectual para nosso tempo porque fugia desse tipo de postura. Aaron e ele são intelectuais com a virtude da autorretidão.

\section{$\mathbf{R M}$}

Talvez esses autores, hoje, fossem críticos da chamada "política identitária"?

\section{AC}

Não sei, mas me parece que Bobbio, assim como Mark Lilla (que tem escrito sobre política identitária), está preocupado com a quebra dos laços sociais. É um movimento que enfatiza não o que há em comum entre os grupos, mas suas diferenças. Bobbio certamente argumentaria pela importância do reconhecimento. Mas apenas reconhecimento não

\footnotetext{
3 Faces of Moderation: The Art of Balance in an Age of Extremes. NYC: Ed. Haney Foundation Series, 2018.
} 
basta, é preciso avançar e buscar o que temos em comum. Os laços sociais que mantêm a República em última instância.

\section{RM}

Você tem escrito sobre moderação. A importância da moderação na política e os desafios e riscos de uma sociedade polarizada - e particularmente para nós, no Brasil, às vésperas de uma eleição bem polarizada - são um debate bem caro. Poderia explicar um pouco sobre a importância da moderação na política? Como redescobrir a moderação na política?

\section{AC}

Boa sorte com a eleição no Brasil! E o Brasil não é o único caso de eleição polarizada. Estamos vivendo um tempo que, pelo que parece, é de intransigência ideológica e de polarização. E aqui nos EUA o nível de tensão é inacreditável. Desde a eleição de Trump até estes dias, com o processo de nomeação do juiz Kavanaugh para a Suprema Corte, o grau de imoralidade e de falta de moderação política está em um nível inédito. Ou talvez já tenhamos visto antes, mas esquecemos (risos). A moderação como eu a defino é uma virtude para as pessoas corretas. É muito fácil nos aliarmos ideologicamente a um dos lados, e os moderados podem ser encontrados não apenas no centro - e é um erro comum associar a moderação ao centro político -, mas em todos e em qualquer lado do espectro político. E, no meu processo de pesquisa para o livro que escrevi sobre esse tema, eu creio que consigo provar que isso é possível. No entanto, devo dizer também que a moderação é uma busca utópica. Frisando que os moderados devem estar em todo o espectro ideológico, eu diria que a luta é contra a tribalização da política. Cultivar o comprometimento sempre deve ser uma prioridade, mas hoje isso ganha uma importância maior do que nunca. Comprometimento passa por cultivar uma mentalidade que é oposta à mentalidade "amigos vs. Inimigos", que sempre foi muito forte na política e cujas raízes remetem ao trabalho do jurista alemão Carl Schmitt - ele próprio pensando pelo espectro da direita, mas essa mentalidade foi adotada por muita gente da esquerda também.

Encontrar o comprometimento é algo muito importante. Aqui nos EUA, a moderação política se perdeu, em parte, com auxílio de alguns instrumentos políticos, como, por exemplo, as primárias eleitorais. Ser moderado em um processo de primárias é estar em maus lençóis. É ser facilmente desafiado por radicais que adotam uma postura de "francoatiradores" e são eles que mobilizam mais eleitores, dificultando que um moderado consiga chegar às eleições gerais. 0 que muitos analistas argumentam é que as primárias favorecem os radicais, mas as eleições majoritárias levam os candidatos ao centro. Toda regra tem exceção e certamente Trump mostra que não foi isso que aconteceu aqui nos EUA. Trata-se de um presidente que divide o eleitorado e alimenta a polarização o tempo todo. Então, passamos a falar que são as instituições que estão fracassando. Isso perpassa 


\section{entrevista}

a geografia do voto, como está distribuído nos distritos eleitorais, etc., até mudanças que afetam o sentido mais amplo da democracia, tornando difícil a moderação na política.

\section{$\mathbf{R M}$}

Sem moderação a democracia está em risco?

\section{AC}

Sim, o risco é grande, pois sem os moderados pouco ou ninguém fala em comprometimento, em diálogo, e muitas vezes nem sequer há a preocupação em conhecer e entender aqueles que pensam diferente. Sem moderação, a própria ideia de diversidade está em risco; portanto, é importante resgatarmos a ideia de moderação na política. Tem sido comum candidatos ganharem sem de fato conseguir a maioria dos votos, mas mesmo assim eles entendem que têm um "mandato" para governar a nação e acreditam - ou querem acreditar - que têm condições de implementar mudanças radicais no país. 0 atual presidente dos EUA, por exemplo, perdeu as eleições majoritárias (no voto popular). Claro que ele recebeu milhões de votos e, pelas regras, ele é presidente dos EUA, mas isso não quer dizer que ele, a partir desse ponto, possa agir de forma indiscriminada, que ele tenha um mandato que lhe dê legitimidade para levar o país com uma agenda radical. 0 fato de essa agenda ser rejeitada pela maioria da população deveria ser já motivo suficiente para uma postura mais moderada politicamente. Na política, muitas vezes o partido ou os atores que hoje estão na oposição podem, em dez anos ou menos, virar governo. Portanto, a mentalidade de que "o vencedor leva tudo", que tem vigorado nos EUA, cria um círculo vicioso e tem sido nociva para o país e para a democracia. Os grandes temas e os grandes debates legislativos ocorrem sem bipartidarismo. Quando a proposta parte de um governo democrata, é preciso maioria democrata para aprovar; quando são os republicanos, a agenda avança com maioria republicana. E isso empobrece o debate e faz a discussão ser áspera e curta.

\section{RM}

E temos alguma saída para isso?

\section{AC}

Eu acho que podemos adotar alguns "pequenos passos". Não tenho uma resposta "macro", como talvez um político poderia dar. No meu cotidiano como professor universitário no programa que já dirigi em Indiana, tento trazer e conversar com pessoas de todos os espectros políticos e devo admitir que isso não é uma tarefa fácil. Eu tenho sido muito criticado, pois, ao abrir o diálogo para ideologias às vezes tão díspares, alguns pares certamente passam a me ver como alguém "impuro" (risos). Algo que podemos fazer é ter a coragem de romper essas bolhas ideológicas. Outro ponto é lembrar-se da importância do diálogo. Como trabalhei no meu livro, é fundamental trabalharmos no 
sentido de mentalidade aberta ao diálogo. E com pequenos passos nós conseguimos lutar contra essa intransigência que está em todos os lados do espectro ideológico.

Há um aforismo de Czesław Miłosz, em The Captive Mind, no qual ele nos conta de um velho judeu da Galícia que dizia que, quando uma pessoa se diz com $50 \%$ de certeza, isso é bom, mas não serve. Quando alguém diz algo com $60 \%$ de certeza, é algo maravilhoso, algo de muita sorte. Portanto, que ele agradeça a Deus por isso. Mas e quando alguém se diz $100 \%$ certo? Nesse caso, o velho sábio diria que isso é algo suspeito, pois qualquer um que tenha $100 \%$ de certeza é um fanático, um lunático, o pior tipo de radical.

Nós, portanto, devemos cultivar as pessoas pelo que escrevemos, pela forma como nos comportamos. Devemos dialogar especialmente com as pessoas que discordam de nós ou de que nós discordamos e assim manter vivo um senso de dúvida. E não achar que aqueles que de nós discordam são "fracos" ou que precisam ser educados (em centros de reeducação) ou mesmo eliminados da vida política.

A consequência da intolerância tem efeitos globais, mas podemos combatê-la começando por baixo. Aqui nos EUA, historicamente há intenso debate sobre a Constituição. Ela funciona bem, mas acredito que estamos em um tempo no qual é preciso parar de venerar a Constituição americana e prestar atenção no que eventualmente precisa de alteração. Não tenho certeza se são coisas fáceis de mudar, mas nós precisamos falar sobre essas coisas. Para além do diálogo, nada deveria ser sagrado, ou, em outros termos, nada deveria ter o status de sagrado a ponto de impedir o diálogo.

\section{RM}

Antes de terminar, não podemos deixar de falar sobre anti-intelectualismo. Em quem ou no que você pensa quando falamos em anti-intelectualismo?

AC

Não sei se posso dar uma boa resposta. Morando nos EUA, eu posso dizer que sempre existiu uma tendência anti-intelectual por aqui. Richard Hofstadter escreveu sobre isso. ${ }^{4}$ E o argumento dele, em certa medida, ainda é válido. Os intelectuais têm papel limitado. Ligue a TV e você verá uma seara de diferentes pessoas, mas raramente intelectuais. John Rawls não estará essa noite num talk show (risos), mesmo ele sendo, talvez, um dos mais notórios filósofos políticos. Em outros tempos, vale lembrar na França, Aaron chegou a participar de talk shows, mas é outro contexto e outra era.

Na universidade e nos círculos em que eu trânsito, deparo também com um antiintelectualismo que parte da tecnocracia da mentalidade tecnocrata. Uma mentalidade corporativa daquele estilo "tempo é dinheiro" e com base nisso passam a julgar um livro, por exemplo, conforme sua capacidade de venda. Quando um professor é avaliado pelas horas de crédito que ele proporciona aos cursos e programas, isso tudo não deixa de ser

\footnotetext{
4 The Paranoid Style in American Politics. NYC: Ed. Harpers, 1964.
} 


\section{entrevista}

um estreitamento da mentalidade e uma perigosa raiz anti-intelectual. É a burocratização não só das universidades, mas de nossas vidas.

\section{RM}

Nosso tempo é também um tempo no qual as teorias conspiratórias parecem ser mais populares. Há também um crescente negacionismo, seja de fatos históricos (como genocídios), seja de problemas contemporâneos, como as mudanças climáticas. Esse contexto exige também um esforço intelectual. Certamente há intelectuais trabalhando e justificando essas visões alternativas ou anti-intelectuais. Os intelectuais não são parte desse problema?

\section{AC}

Os intelectuais podem ser parte do problema - e certamente o são - e muitos intelectuais gostam dessa vida burocrática, mas nesse ponto não vejo muitos problemas vindo daí. Da forma como eu penso os intelectuais, trata-se de um trabalho elevado. Nem todo acadêmico deve ser chamado de intelectual e nem todo intelectual quer estar ou está na academia. 0 intelectualismo é uma vocação e, como tal, é para poucos. Ser um intelectual, nesses termos, é um "chamado" que certamente cobra seu preço. Nesse ponto, acho que devemos também diferenciar o intelectual do "scholar" (no termo em inglês), aquele erudito, o estudioso na "torre de marfim" que escreve para um público restrito e limitado. Já o intelectual tenta ter uma presença e um impacto maiores na esfera pública e busca atingir um público mais amplo.

De fato, intelectuais têm sua responsabilidade. Ao criar "tribos" e negar a realidade, alimentam muitas vezes a desinformação, mas vale lembrar um autor francês, Julien Benda, que fala em clerc (no termo em francês), que é diferente de intelectual. A ideia que o termo clerc proporciona é mais compreensível que o termo "intellectual", tal como usamos em inglês. E, ao perder essa dimensão de clerc, os intelectuais deixam de ser intelectuais e passam a ser operadores.

A relação - para não dizer casamento - entre intelectuais e política é uma relação difícil. Intelectuais que entram na política às vezes o fazem de forma desastrosa e, nesse ponto, é importante também aos intelectuais praticar a prudência antes de se lançarem nas batalhas políticas. Podemos atribuir também aos intelectuais um papel de higienização. Essa foi a ideia que Claude Lévi-Strauss discutiu com Raymond Aaron. Os intelectuais teriam a função de purificar o ar que respiramos. Portanto, os intelectuais que não conseguirem fazer essa higienização não seriam dignos do título (risos).

${ }^{5}$ Cf. debate La trahison des clercs, de Julien Benda, disponível em francês em: http://classiques.uqac.ca/ classiques/benda_julien/trahison_des_clercs/benda_trahison_clercs.pdf. Acessado em: 2/10/2018. 
entrevista

$\mathbf{R M}$

Essa ideia não deixa de ser utópica, não? Você arriscaria fazer um balanço do pensamento utópico em nosso tempo?

AC

Certamente há tentações utópicas e é fato que intelectuais emprestaram seu nome e seu prestígio para projetos utópicos. A ideia de comunismo talvez seja o exemplo mais claro. Hoje em dia, o potencial para uma utopia não vive os melhores dias. Parece-me que vivemos mais um momento de distopias. Utopia e distopia, sem dúvida, são uma discussão paralela a essa que fizemos sobre intelectuais e anti-intelectualismo. Um ponto importante é a ideia de "senso comum", que por si mesma é difícil de definir. Trata-se de uma metáfora para muitas coisas. Nós podemos desejar coisas grandes e pensar em temas amplos, mas é importante também ter os pés no chão e evitar que as ideias e aspirações não virem um meio para as ambições de pessoas sem ética.

\section{RM}

Muito obrigado pela entrevista.

AC

Obrigado. 